\title{
EXCURSION TO THE SMART DIMENSION THROUGH MATHEMATICS: SIGNIFICANCE OF OUTCOME-BASED EDUCATION
}

\author{
Nushrat Hashmi \\ Lecturer \\ Department of Mathematics \\ CCN University of Science \& Technology, Bangladesh \\ Monica Rani Das \\ Lecturer \\ Department of Mathematics \\ CCN University of Science \& Technology, Bangladesh \\ Ikbal Ahmed \\ Lecturer \\ Department of CSE \\ CCN University of Science \& Technology, Bangladesh
}

\begin{abstract}
The advancement of a smart society depends to a large extent on the standard of the higher education system. The fourth Industrial Revolution (FIR), or smart industry, is the trend related to artificial intelligence, changing various aspects of life, especially the education system. The flow of the smart industry, spurring Bangladesh to accept the technologies of the FIR. The drift of FIR will drop a strong impact on our graduates. The smart industry needs the efficiency of Science, Technology, Engineering, and Mathematics (STEM). Mathematics is a scaffold to the next industrial revolution. So, our university education system should be convenient to set up our graduates all around the smart world and overcome the industrial requirements; it is compulsory to adopt Outcome-Based Education (OBE). OBE templates were approved at the 157th meeting of the University Grants Commission of Bangladesh (UGC) on 06 February 2020. Recently, UGC has requested that all universities modify their undergrad educational plans depending on the Outcome-Based Education (OBE) layout. The purpose of this article is to look at the significance of skilled Mathematics alumni for the smart world, and we also examine the challenges of actualizing Outcome-Based Education (OBE).
\end{abstract}

Keywords: Fourth Industrial Revolution(FIR), Smart industrial requirements, Education System, Outcome-based Education (OBE).

\section{INTRODUCTION}

We stay close to the unstable edge of a mechanical change that will, on a fundamental level, adjust the way we live, work, and relate to one another. In its scale, expansion, and multifaceted nature, the change will not be typical for anything humankind has experienced already. We don't 
yet know precisely how it will spread out; anyway, one thing is clear: the response to it ought to be facilitated and broad, including all accomplices of the overall nation, from individuals all in all and private regions to the insightful network and regular society. Like the transformations that went before it, the Fourth Industrial Revolution can raise worldwide pay levels and improve the personal satisfaction for populaces around the globe.

Developing the first Industrial Revolution, which used water and steam ability to mechanize creation, the second, which used electric ability to make huge scope, producing and the third, which used devices and information advancement to automate creation; the fourth Industrial Revolution is taking computerization higher than at any other time, darkening the lines between the physical, progressed, and natural circles and utilizing advances to perform assignments recently completed by people.

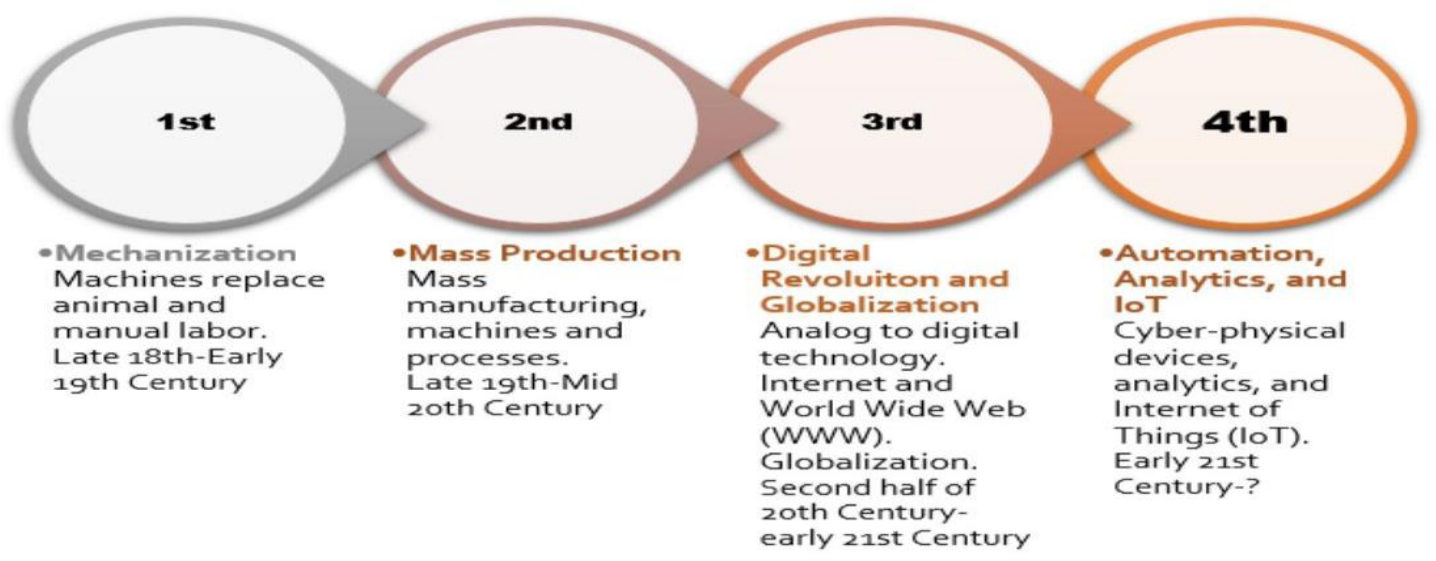

Source: How Will We Work? How Will Your Job Change? (2025)

A new report found that computerization will substitute 800 million incompetent laborers worldwide by 2030 (World Economic Forum, 2020). To get the advantage of new technological opportunities, employees need to be ready with 21 st-century aptitudes, consisting of essential thinking, participation, basic reasoning, creativity, analytic thinking, and flexibility.

Industry 4.0 that grasps the computerization in savvy industrial facilities requires improved limits in Science, Technology, Engineering, and Mathematics (STEM). The STEM aptitude of Workers not just development essential logical information yet additionally utilizes this information to plan and fabricate new products. Math energizes coherent thinking, basic thinking, innovative thinking, theoretical or spatial reasoning, critical thinking capacity, and even viable relational abilities. Moreover, mathematics is the language of research and creative work in applied and mechanical fields. As the speed of social and mechanical change expands, these abilities will become progressively significant. So, it's essential to take considering the significance of mathematics for new dimensions. As a readiness to take up the difficulties of the IR 4.0, graduates should be presented with suitable aptitudes to guarantee their work and to stay working in the always-changing industry and innovation climate.

\section{RESEARCH OBJECTIVE}

In this study, we will discuss the significance of mathematics through Outcome-Based Education (OBE) to confront the flow of the Fourth Industrial Revolution (FIR), and we will find out the main challenges of implementing OBE in our country, moreover to overcome the challenges of $\mathrm{OBE}$ we will give our proposals. 


\section{METHODOLOGY}

The method utilized in finishing this paper is library research. This paper's information and data were gathered from research reports, reliable papers, journals, seminars, and electronic sources. To know the present and future state of the job market, we read several reports based on challenges of FIR, and we also collected information from annual reports over the period of 2017 to 2020 of World Economic Forum and Price water house Coopers (PwC). We studied various articles, magazines, reports based on FIR and OBE to enrich our research. Furthermore, to get a clear idea of OBE, we take help from the template of OBE provided by the University Grants Commission of Bangladesh (UGC).

\section{LITERATURE REVIEW}

In the hour of globalization, conventional instruction structure is losing its importance. These days, everything changes quickly and interminably. More aptitudes are required to work with smart-making progression. The World Bank assessed in 2019 that around 57 percent of occupations in OECD (Organization for Economic Co-operation and Development) nations, 77 percent occupations in China, and 47 percent of occupations in the USA would be in danger because of the expansion of robotization. Another report shows that $60 \%$ in lower Education, $48 \%$ in medium, and $19 \%$ in high-level training occupations will be unstuck by means of computerization (PricewaterhouseCoopers BV, n.d.).

The fitness bundles, which administrators see as rising in prominence in the main spot up to 2025, join social events, for instance, fundamental thinking and examination similarly as issue solving, which have stayed at the most noteworthy purpose of the arrangement with year-on-year consistency. This year's late-emerging capacities in self-organization, for instance, dynamic learning, strength, stress obstruction, and versatility (The Future of Jobs Report 2020| World Economic Forum, 2020). The relative importance of different skill groups:



Source: The Future of Jobs Report (2020) | World Economic Forum (2020) 
Mathematics instructors have superpowers. They have the ability to comprehend and esteem mathematics. What is the premise of their force? It is their arithmetic instructive and content information. Not exclusively would they be able to do mathematics? However, they can build a learning climate where their understudies create theoretical knowledge and profound learning. They utilize the most recent advancements in innovation to help their fight with the powers of obscurity and innumeracy (White, 2011).

Numerical proficiency is fundamental to STEM schools. An office in managing vulnerability and information is integral to settling on proof-based choices, including moral, financial, and ecological measurements (Australia. Office of the Chief Scientist., 2013).

Different reports, for example, those from the (Australia. Office of the Chief Scientist., 2013, 2014) and the Australian Council of Learned Academies (Marginson et al., 2013) moreover stress the significance of all understudies having solid STEM information, aptitudes, and imaginative miens.

(English, 2015) also explained Mathematics education gives basic substance and cycles that associate the STEM orders, and math ought to be raised to the apexes of the STEM mountain reach. We should promise it stays there with its commitments saw and applauded.

STEM training all in all, and particularly mathematics schooling, has all the earmarks of being the areas pre-famously fit for encouraging 21 st-century abilities. Indeed, aptitudes, for example, basic reasoning, issue presenting, critical thinking, working together, and conveying, have just been on the plan of science teachers for quite a while. These aptitudes are viewed as instrumental in issue-focused instructional methodologies that perceive that information isn't sent and target supporting understudies in building mathematics (Gravemeijer et al., 2017).

Nakkeeran et al. (2018) stated that more aptitudes are needed to work with, quick creating technology along these lines to conquer the necessity, it is obligatory to shift from a traditional education system to Outcome-Based Education (OBE), which incorporates Program Outcomes (PO), Learning Outcomes (LO), and Course Outcomes (CO).

Tezer (2019) stated that the teaching done by utilizing mathematical modeling along with STEM expands the understudies' inspiration toward the exercise; they learn better by focusing their consideration regarding the matter, leaving a beneficial outcome for them; and the understudies' prosperity and perspectives toward the exercise increment. He also further added taking care of genuine issues later on through STEM and mathematical modeling will keep on assuming a significant job in giving inventive and imaginative critical thinking points of view in the social and monetary advancement of the nations.

The FIR will bring a significant test for the education sector as Bangladesh elevates training to its understudies through instructional teaching methods. A Large scope professional and viable preparing program should have been incorporated with the current education system (Rumi et al., 2020). It refers to any learning activity in which not all answers and exchanges occur simultaneously but may be completed when a participant chooses (typically within a given time frame). Participating in an online forum or taking an online quiz are examples of asynchronous activities where learning occurs between two or more individuals. Teachers and students must use hybrid teaching to preserve social distance while continuing their educational pursuits. (Ahmed et al., 2020). 


\section{OUTCOME-BASED EDUCATION IN MATHEMATICS}

Mathematics plays a cardinal role in every sector of science, engineering, and technology. Fuzzy mathematics forms a branch of Mathematics that strongly impacts automation with Artificial Intelligence (AI). IR 4.0, or smart industry, is the trend towards automation related to artificial intelligence. Mathematical Optimization (MO), another branch of Mathematics, provides an analytical process for minimizing cost and maximizing profits and efficiency for industry. Similarly, most of the pure and applied mathematics branches have a vast application in the technological revolution. But our mathematics graduates are still unconscious of their importance in this stream of globalization. Efficient mathematics graduates will play a vital role in the smart industry and be able to create a new smart nation to confront the drift of smart technologies. Outcome-Based Education (OBE) is a smart system in which students know their purpose of learning clearly. At the beginning of courses, the teacher provides a smart curriculum consists of Program Outcome (PO), Learning Outcome (LO), and Course Outcome (CO). In $\mathrm{OBE}$, great sharable assets, evaluations, and rubrics are intended to help learning results. OBE is a blend of three kinds of skill: a) down to earth: realizing how to get things done, capacity to decide, b) principal: understanding what you are doing and why c) intelligent: learn and adjust through self-reflection; apply information properly and mindfully. Students assume liability for their own learning and are propelled by criticism and certification of their value. $I t$ is high time to make our math graduates capable of the new dimension through OBE.

\section{Advantages of OBE}

- The aim of OBE is to expand the knowledge, basic reasoning capacity, and skill of the understudies.

- OBE is a student-oriented system.

- Provide a clear idea about their purpose of learning.

- It makes understudies more mindful.

- Increases students are thinking ability.

- Learners are assessed on an ongoing basis.

- Content is coordinated, and learning is important and associated with genuine circumstances.

- Enhances the communication skills of students.

- Expands student's adaptability and flexibility.

\section{Comparison of TE AND OBE}

Traditional Education (TE) is exceptionally subject to hypothetical parts of learning. This approach is totally instructor-focused. This training technique is regularly reprimanded on the grounds that: (i) little consideration is paid to understudies if they comprehend the idea, (ii) it doesn't draw out the best in understudies, and (iii) it doesn't include students in learning (Hassan, 2021).

Outcome-Based Education implies centering and arranging everything in an instructive framework around what is basic for all understudies to have the option to do effectively toward the end of their learning encounters. This implies beginning with an away from what is significant for understudies to have the chance to get then sorted out educational plan, guidance, and appraisal to make sure this adapting eventually occurs (Spady, 1994). 


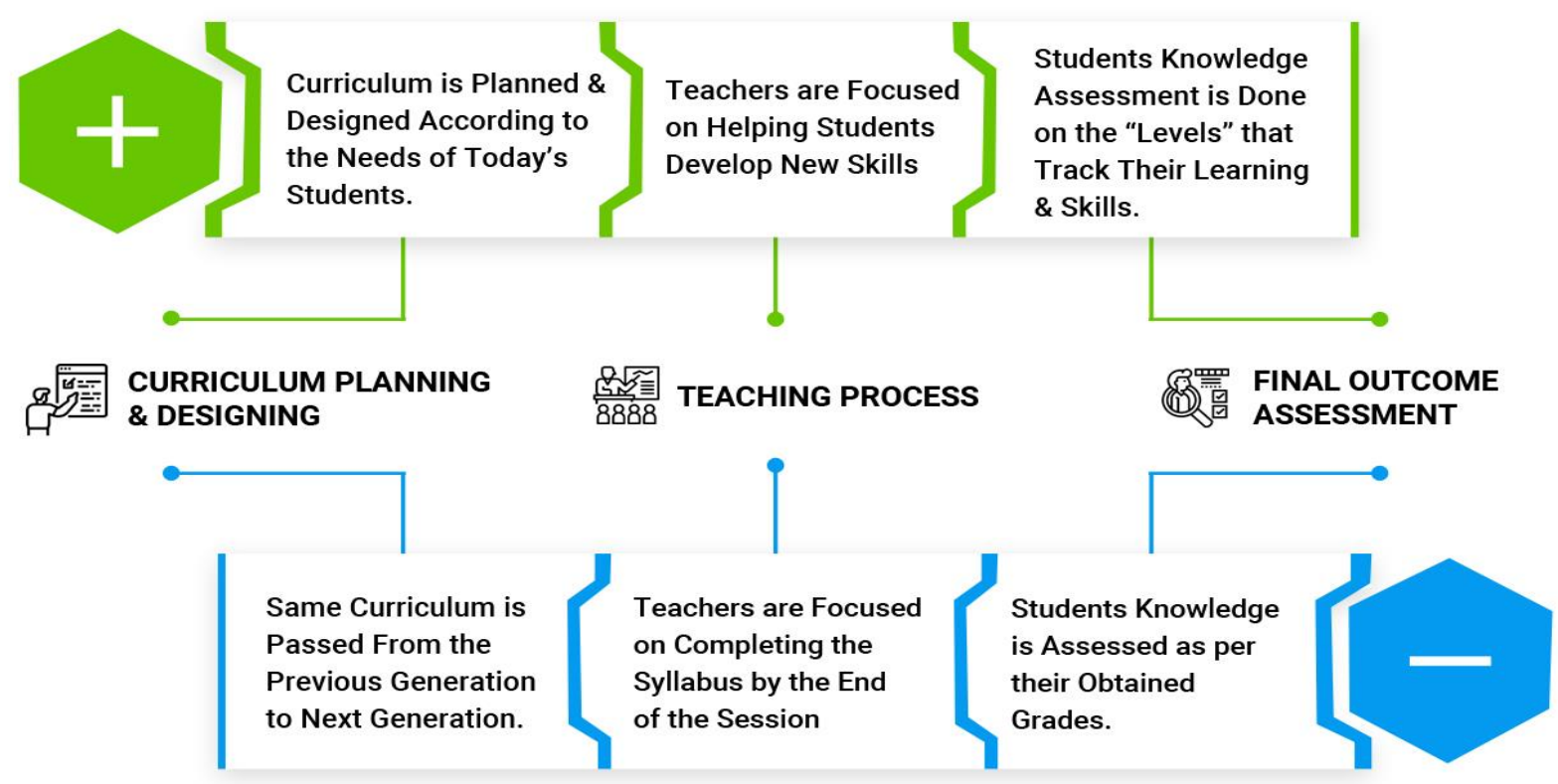

OBE System VS Traditional Education System (Ashish Vyawhare, 2020) Source:(Outcome Based Education vs. Traditional Education | OBE System, n.d.)

\section{PRESENT SITUATION OF OBE IN BANGLADESH}

In March 2017, Bangladesh Accreditation Council (BAC) was set up and began working in May 2020. The main purpose of BAC is to advance and guarantee quality affirmation in advanced Education in Bangladesh through executing capability structure and authorize the scholarly projects and advanced education organizations. To implement the OBE curriculum, the University Grants Commission of Bangladesh (UGC) has taken steps in 2018 to set up a standard format for the universities of Bangladesh to prepare their curriculum of existing and upcoming courses. After a series of conversations on the drafted OBE layout readied as a rule by a specialist council in 2019 and opinions got from the different specialists, at last, the formats were affirmed in the 157th gathering of the Full Commission of UGC on 05 February 2020. UGC sent the soft copy of the OBE template to all universities on 17 June 2020 and requested to update their curriculum on the Outcome-Based Education (OBE) format.

\section{CHALLENGES OF IMPLEMENTING OBE}

The selection of OBE brings numerous difficulties for us. We recognized some significant challenges to execute OBE as follows:

- Lack of training: The idea of OBE is new for our teachers. The main challenge of implementing OBE is the lack of proper training in certain aspects like the design of curriculum, writing of Course Outcomes (CO), Program Outcomes (PO), Assessment and evaluation processes.

- Lack of proper knowledge of our students about OBE: OBE is a student-centered method. To implement OBE properly, students' participation is very important. But most of our students are not aware of the importance of OBE, which will make it difficult to communicate with our students. 
- Lack of well-equipped laboratories: Lab facilities are fundamental in OBE to upgrade students' understandings of theories in science, engineering, and technology education. Lack of well-arranged laboratories will be the major problem for us.

- Financial instability: As a developing country, we have limited financial resources. Training, modern lab equipment, a smart library, organized educational institutions, sufficient manpower are essential for OBE, which is impossible without strong financial support.

- Lack of proper research: Unfortunately, due to a lack of relevant researches, we still don't have a clear idea about the genuine condition of our students, teachers, and educational institutions

\section{PROPOSAL TO CONFRONT DIFFICULTIES OF OBE}

Adoption of $\mathrm{OBE}$ is the demand for new technological flow. To achieve the goal of a smart society through OBE we have to prepare our educational institution with some significant elements as follows:

- Training: Teachers are the main driving force to implementing OBE. To prepare Program Outcome (PO), Course Outcome (CO), and Program Educational Objective (PEO) through Bloom's Taxonomy, our teachers need proper training. During training, teachers will be able to practice the hypothesis to enrich their idea about OBE.

- Spontaneous participation of students: The OBE system engages students by continuous assessments and enhances their flexibility to adopt new ideas in a frank way. To ensure students' participation, teachers have to motivate them by spreading the advantages of OBE. Spontaneous participation of students is the most important fact in implementing OBE because OBE is students centered system.

- Convenient curriculum: Convenient curriculum has a cardinal role in OBE. To implement OBE, it is necessary to prepare a smart curriculum with vision, mission, Program Educational Objectives (PEO), and Program Learning Outcomes (PLO).

- Long-term planning: For OBE, long-term planning should be taken. At the starting of the program, it is essential to provide students a clear idea about their learning outcomes after 4/5 years. Moreover, teachers can categorize students with their creativity and skills by continuous assessments from the beginning and motivate students for their future life on the basis of their capability. In this continuous process, our graduates will be able to identify their worth to prepare themselves for the future.

- Financial stability: To ensure training, modern lab equipment, smart library, organized educational institution, sufficient manpower, and other equipment of smart Education, we need to make an effort to increase our financial sources.

- Industrial collaboration: Our educational institution should make more collaborate with national and international industries to know their smart industrial requirements to make our generation ready for new flow through OBE.

- Relevant Research: More research with a larger sample should be performed to get a deeper insight into developing our education system. Furthermore, relevant research will help us to bridge the gap between education systems and industrial needs.

- Flexibility to adopt new ideas: To cope with the latest technological flow, our curriculum and education system should be flexible. After every certain period, it should be revised to make it convenient for our students to prepare them for the new flow 


\section{RESEARCH FINDINGS}

- The flow of FIR will bring authentic challenges for developed and developing countries. Due to advanced technologies and skilled human resources, developed nations will face less risk than developing nations. As a developing country, we have many difficulties, but the unskilled human resource is one of the major problems for us. To cope up with the new flow, our country needs imaginative, skilled, adaptable, creative, enterprising alumni who can face the difficulties of the present changing workplace.

- The smart technological flow needs the efficiency of STEM, especially mathematical knowledge. Math expands intelligible reasoning, essential reasoning, creative reasoning, hypothetical or spatial thinking, basic reasoning limit, and even feasible social capacities, and these are the most important component of the fitness bundle for the smart industry. Every student from different subjects or fields needs basic mathematics skills, and it's clear that skilled mathematics educators can help make a skilled nation confront the new technological flow. In addition, Mathematics has huge applications in engineering, science, and technology, and we know it is the language of technology. So Mathematic is the platform to the following modern transformation. Due to a lack of proper guidance, most of our mathematics students are still oblivious to the significance of mathematical knowledge.

- It's a convenient time to utilize the advantages of Outcome-Based Education (OBE) to make our graduates ready for the new technological world. OBE is learners centered system. It gives students a clear idea about their learning purpose by providing a smart curriculum consists of Course Outcome (CO), Program outcome (PO), Learning Outcome (LO), and it helps to make students more conscious about their aim. In this smart teaching system, learners are assessed on an ongoing basis through Bloom's taxonomy, which increases students thinking ability, communication skills, adaptability, and flexibility.

- UGC's template of OBE will help bridge the gap between the higher education system and industrial needs. Most of the universities of Bangladesh already take the initiative to update their curriculum with the template of OBE given by UGC. But adoption of OBE brings many challenges for us. To confront the challenges of OBE, we need to prepare our higher education sector with many fundamental components such as training, financial stability, relevant research, flexibility, organized laboratory, long-term planning, and most importantly, we have to ensure students' spontaneous participation.

\section{CONCLUSION}

Smart technologies will drop a strong impact on many aspects of life, especially the education system. Mathematics is the language of a new technological dimension. But unfortunately, our graduates are not properly conscious of their role in the present flow of smart technologies. The smart education system can give them appropriate direction to understand their importance for our country to face the drift of FIR. In this paper, we discussed the significance of skilled graduates through OBE. We also find out some challenges of implementing OBE and give some proposals to overcome them. Finally, the study suggests that to confront the flow of FIR, we need more research work in our country. We should take the proper initiative to face the challenges of implementing OBE in our education system. 


\section{REFERENCES}

Ahmed, I., Eunus, M., Helal, S., \& Banik, N. (2020). Hybrid Instruction: Post COVID-19 Solution for Higher Education in Bangladesh. International Journal for Modern Trends in Science and Technology, 06, 20-25. https://doi.org/10.46501/IJMTST061004

Australia. Office of the Chief Scientist. (2013). Science, technology, engineering and mathematics in the national interest : a strategic approach : a position paper. 34.

Australia. Office of the Chief Scientist. (2014). Science, Technology, Engineering and Mathematics: Australia's Future. Retrieved from https://www.chiefscientist.gov.au/2014/09/professor-chubb-releases-science-technologyengineering-and-mathematics-australias-future

English, L. (2015). STEM: Challenges and opportunities for mathematics education. In T. Muir, J. Wells, \& K. Beswick (Eds.), Proceedings of the 39th Meeting of the International Group for the Psychology of Mathematics Education, PME 39 (Volume 1) (pp. 4-18). IGPME - The International Group for the Psychology of Mathematics Education. https://eprints.qut.edu.au/87506/

Gravemeijer, K., Stephan, M., Julie, C., Lin, F. L., \& Ohtani, M. (2017). What mathematics education may prepare students for the society of the future? International Journal of Science and Mathematics Education, 15, 105-123. https://doi.org/10.1007/s10763-0179814-6

Hassan, M. M. S. (2021, 11 June). Covid-19: Highlighting the necessity for rethinking higher education | theindependentbd.com. https://m.theindependentbd.com/post/264986

How Will We Work? How Will Your Job Change? (2025). Retrieved 20 August, 2021, from https://www.td.org/insights/2025-how-will-we-work-how-will-your-job-change

Marginson, S., Tytler, R., Freeman, B., \& Roberts, K. (2013). STEM: country comparisons: international comparisons of science, technology, engineering and mathematics (STEM) education. Final report.

Nakkeeran, R., Babu, R., Manimaran, R., \& Gnanasivam, P. (2018). Importance of Outcome Based Education (OBE) to Advance Educational Quality and enhance Global Mobility. International Journal of Pure and Applied Mathematics, 119(17), 1483-1492. http://www.acadpubl.eu/hub/

Outcome Based Education vs. Traditional Education | OBE System. (n.d.). Retrieved 20 August, 2021, from https://www.iitms.co.in/blog/outcome-based-education-system.html

PricewaterhouseCoopers BV (n.d.). PwC Annual Report 2017/2018. https://www.pwc.nl/nl/assets/documents/pwc-annual-report-2017-2018.pdf

Rumi, M., Nahid, N., Makhdum, N., \& Rashid, M. (2020). Fourth Industrial Revolution in 
Bangladesh: Prospects and Challenges. Asian Journal of Social Sciences and Legal Studies, 104-114. https://doi.org/10.34104/ajssls.020.01040114

Spady, W. G. (1994). Outcome-based Education : critical issues and answers. 207.

Tezer, M. (2019). The Role of Mathematical Modeling in STEM Integration and Education (pp. 1-14). https://doi.org/10.5772/intechopen.88615

The Future of Jobs Report $2020 \mid$ World Economic Forum. (2020). https://www.weforum.org/reports/the-future-of-jobs-report-2020

White, A. L. (2011). School Mathematics Teachers Are Super Heroes. Southeast Asian Mathematics Education Journal, 1(1), 3-17. https://doi.org/10.46517/SEAMEJ.V1I1.6

\section{Copyrights}

Copyright for this article is retained by the author(s), with first publication rights granted to the journal. This is an open-access article distributed under the terms and conditions of the Creative Commons Attribution license (http://creativecommons.org/licenses/by/4.0). 